International Academic Conference on Management \& Economics

\title{
Mean-Variance Analysis in Pension Fund
}

\section{Investment}

\author{
Yuanting Miao
}

Shanghai University, China

\begin{abstract}
The paper studies pension fund investment in both developing and developed countries in order to improve the pension fund management and improve the benefits of pension investment. We use the Modern Portfolio Theory and mean-variance analysis to analyze pension fund investment. We select data of pension fund assets in eight countries: Australia, Canada, United Kingdom and the United State, Indonesia, Kenya, Thailand and Mexico from 2001 to 2017 from the OECD. With a comparison between countries, we find that there is a large gap between developed countries and developing countries. Value of pension assets in developed countries is significantly larger than that of developing countries, where the United States has an overwhelming superiority. However, developing countries have a higher average rate of return, which shows a strong growing tendency. Through analysis in average rate of return and standard deviation, we find that most countries have relatively high average return with relatively high volatility. Based on the mean-variance model, we make portfolios of pension fund assets among countries with different weights on each country and obtain an efficient
\end{abstract}




\section{International Academic Conference on Management \& Economics}

frontier. We find that it is possible to make an optimal portfolio of pension assets of different countries as a whole to maximize the overall interests at a given risk.

Keywords: Modern Portfolio Theory, mean-variance analysis, pension funds, optimal portfolio, efficient frontier

\section{Introduction}

Pension fund assets play a significant role in financial market for each country, so it is important to study the pension fund investment. From the perspective of national social welfare, pension funds provide a guarantee for residents when they get retired. For government finance, pension funds is a large sum of financial assets which makes a balance between financial revenue and payment. Pension fund assets can be regarded as an investment technique, which pay benefits for retired employees. Nowadays, pension fund investment experiences a growth in scale in almost all countries, although aging of population and fluctuation of financial indexes stress a lot on pension system. With the improvement of the pension system and the increase of fund asset scale, pension fund assets control a relatively large amount of money. With the aim to improve the pension fund management in a relevant systematic way, it is important and essential to analyze the overall situation of pension fund system. Many studies have applied the theory of investment combination to the pension fund system, which is always the first choice to optimize financial investment. In this paper, we also use the theory of investment combination to study pension asset investment. A lot of attention has been paid to only one country on how to allocate assets in its own pension fund system. Our paper, however, tries to relate different countries and make a combined portfolio among these countries. 


\section{International Academic Conference on Management \& Economics}

The paper is organized as following. We will review the history of pension funds and the development of Modern Portfolio Theory and mean-variance model in Section 2. In Section 3, we will explain the mean-variance model in detail. Then we will apply the model to pension fund assets in 8 different countries and verify the usability of the model in Section 4. Section 5 summarizes the paper and discusses some drawbacks of our model.

\section{Literature Review}

Pension funds, as known as superannuation funds in some countries, pay benefits for retired workers. They are normally considered as the investment pools. They can be classified into two types: defined benefit and defined contribution. Defined benefit is the plan where employees are guaranteed to gain definite retirement commitments, unaffected by the fund performance. It is what commonly regarded as 'pensions. The defined contribution is the scheme where employees' retirement income is affected by how well the fund performs.

Pension funds have a long historical standing in some countries. For example, according to OECD (2018), United States started the plan for public sector employees from 1857 and Canada launched its first employer-sponsored scheme in 1874. Pension assets develop with a growing achievement in investment due to the prosperity of the economy. Since 2002, the positive rate of return of pension funds investment has been presented in most countries (OECD, 2018). Most countries have realized that the rate of return of pension funds investment are positive since 2002 (OECD, 2018). However, the increasing life expectancy and interest rates lead to the higher pension outflows and the burden of the pension system, which may become a problem of concern (Clark and 


\section{International Academic Conference on Management \& Economics}

Monk, 2006). A lot of attention has been paid to the scheme, because pension funds control a large sum of money and dominate the world's financial markets. Bodie (1988) believes that as a tax shelter for corporates, the pension funds can definitely help maximize firm's value. It is undeniable that pension funds play an important role in the development of society and national wealth (Green and Clark, 2000). Garon (2016) also mentions that pension funds improve policy outcomes.

Portfolio is a combination of financial assets such as stocks, bonds and currencies. A desirable portfolio emphasizes high stability and liquidity, as well as high level of return

and low risk. The concept of portfolio is first introduced by Markowitz (1952), with the aim to study the relationship between the investors' expectations of future performance of their investment in financial assets and their final choice of portfolio. There is a typical rule called the 'expected returns-variance of returns' rule, which gradually perfects into a set of systematic theory named as Modern Portfolio Theory (MPT). The main part of this theory is mean variance analysis. It is a technique that is proposed to solve the problem of portfolio selection (Markowitz, 1952). The main idea is to maximize the average return at a given rate of risk provided that investors are rational Here, the mean of portfolio is as an indicator of average return and the variance is used to measure the related risk. Since then, MPT has been applied to a wide range of areas. Lubatkin and Chatterjee (1994) extend the MPT into the corporate diversification for corporate risk management. The mean-variance analysis is applied to solve the classic problem of British capital export in the 19th century (Goetzmann and Ukhov, 2006). The MPT also can be used in water planning to explain the future uncertainties such climate fluctuations (Marinoni, Adkins and Hajkowicz, 2011).

There are some problems of the classical MPT in practice. Damghani (2013) shows that there are some criticisms for mismatching between theory and the real world. Jacoby, 


\section{International Academic Conference on Management \& Economics}

Li and Wang (2018) also point out that the offset of accounting information may lead a mistake in optimal portfolio selection. Even though the MPT has limitations, it is one of the most widely adopted techniques when making investment decisions. Its applications are influential in various fields such as regional science, social psychology and information retrieval.

It is worth noticing that the asset allocation for pension fund is essential for a clear understanding of economics and society (Green and Clark, 2000). Dutta, Kapur and Orszag (2000) introduce mixed funded-unfunded systems based on a mean-variance model and they obtain diversified risk, which proves to be desirable. Højgaard and Vigna (2007) discuss the mean-variance approach to the defined contribution pension

scheme and compare this approach to other target-based investment strategies. They find that other strategies can be formulated as a mean-variance optimization problem. Consistently, minimizing the risk and maximizing the benefit simultaneously in a stochastic defined benefit pension plan is formulated as a bi-objective issue of meanvariance by Josa-Fombellida and Rincón-Zapatero (2008). Moreover, Yao et al. (2014) and Wu and Zeng (2015) utilize mean-variance analysis in multi-period asset allocation for defined contribution pension funds to control risk and optimize the benefits. In both papers, numerical results show that the mean-variance analysis works well. 


\section{International Academic Conference on Management \& Economics}

\section{Methodology}

The mean-variance model is based on some assumptions. We give a list of simplified assumptions and we will describe them briefly. For complete list of assumptions and more detailed explanations, we refer to Markowitz (1987).

- Investors are risk averse, which indicates that investors are willing to purse higher profits at a given level of risk or prefer lower risk with certain returns.

- Investors have same risk assessment. Specifically, all the investors are provided by information and their sale or purchase depends on an identical assessment of the investment and all have the same expectations from the same investment.

- Investors are price takers, which means they cannot change market prices. They can make an arbitrary combination of assets. They do not affect the assets price.

- The market is complete, where all information is available, which implies expected returns and variances are known.

- There are no transaction costs and taxes, which means the net changes of wealth for investors are zero.

- Investors can purchase any amount of any asset, which means there is no requirement that the number of assets owned should be an integer.

The above assumptions are idealized and not realistic in real-world markets.

We consider a portfolio and denoted it as $p$. Assume there are $n$ assets in this portfolio. We denote the return of asset $i$ as and the expected return of asset $i$ as $E\left(R_{i}\right)$, for $i=$ $1, \ldots, n$. Let $w_{i}$ be the amount invested in asset $i$, it is the weights of asset $i$ in the 


\section{International Academic Conference on Management \& Economics}

portfolio with $\sum_{i=1}^{n} w_{i}=1$. The expected return of the portfolio is measured by the weighted average return of assets, which is given by

$n$

$$
\left(R_{p}\right)=\sum_{i=1} w_{i}\left(R_{i}\right)
$$

Risk is the variability between possible outcomes and expected values. Basically, it is classified as systematic risk and unsystematic risk. According to MPT, unsystematic risk will not be considered in the mean-variance analysis. Risk can be measured by the standard deviation of a portfolio. Suppose there is a portfolio consisting of asset $i$ and asset $j(i=1, \ldots \mathrm{n} ; j=1, \ldots \mathrm{n} ; i \neq j)$. We denote $\sigma_{p}$ as the standard deviation of the portfolio and $\sigma^{2} p$ as the variance of the portfolio-

$$
\begin{aligned}
& \text { (2) } \sigma^{2} p=\sum \sum w_{i} w_{j} \sigma_{i j} \text {, } \\
& i=1 j=1 \\
& \sigma_{p}=\sqrt{\sigma^{2}},
\end{aligned}
$$

where $w_{i}$ stands for the weighting of asset $i$ and $w_{j}$ is the weighting of asset $j . \sigma_{i j}$ is the covariance between asset $i$ and $j\left(-1 \leq \sigma_{i j} \leq 1\right)$. As equation (3) shows, the risk of a portfolio not just depends on the variance of each asset but also the covariance between different assets. It suggests that by choosing different assets, we can diversify the risk of investment.

In the financial markets, we assume that rational investors want to maximize the returns given a certain level of risk or to minimize the risk given a certain level of return. The efficient frontier is an efficient tool that helps investors to make investment decisions. 


\section{International Academic Conference on Management \& Economics}

Portfolios on the efficient frontier have highest return at a certain risk. Portfolios below the curve are sub-optimal because their returns are lower than the highest level. Portfolios clustered to the right of the curve are sub-optimal because the risk is higher than that of the optimal choice at the given level of return.

Risk aversions expect higher return when they face higher risk. According to the MPT, we can construct a portfolio to balance return and risk. It means that we can obtain an optimal portfolio that achieves the highest returns with reasonable degree of risk or the lowest level of risk at a provided return. We use $\mathrm{x}$-axis and $\mathrm{y}$-axis to present calculated risk and return, respectively. Points standing for the optimal combination converge into a line, which is widely as known as efficient frontier line. Optimal portfolios on the efficient frontier are more likely to have more ideal effect of diversification. When making investment decisions, risk-averse investors who prefer lower-risk option will choose securities that are on the left end of the efficient frontier line denoted as A. However, risk-seeking investors who are highly tolerant to risk more likely to choose portfolios on the right end of the line denoted as B.

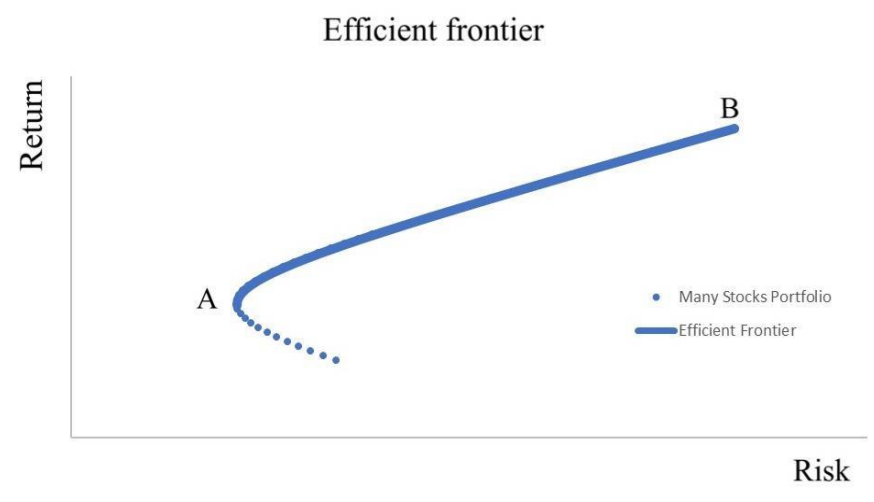

\section{Data Analysis}

We analyze the performance of pension fund investment in eight different countries and we divide these countries into two groups: developed countries including Australia, Canada, United Kingdom and United State and developing countries including 


\section{International Academic Conference on Management \& Economics}

Indonesia, Kenya, Thailand and Mexico. Data of pension fund assets is from 2001 to 2017 and obtained from the official website of OECD. Because the gap of pension fund assets between countries is large, it is difficult to present data in a same figure. This guarantees that the data in each group is at a similar level and can help clearly analyze and compare the pension fund assets by groups.

Figure 1. Total pension fund assets in developed countries from 2011 to 2017

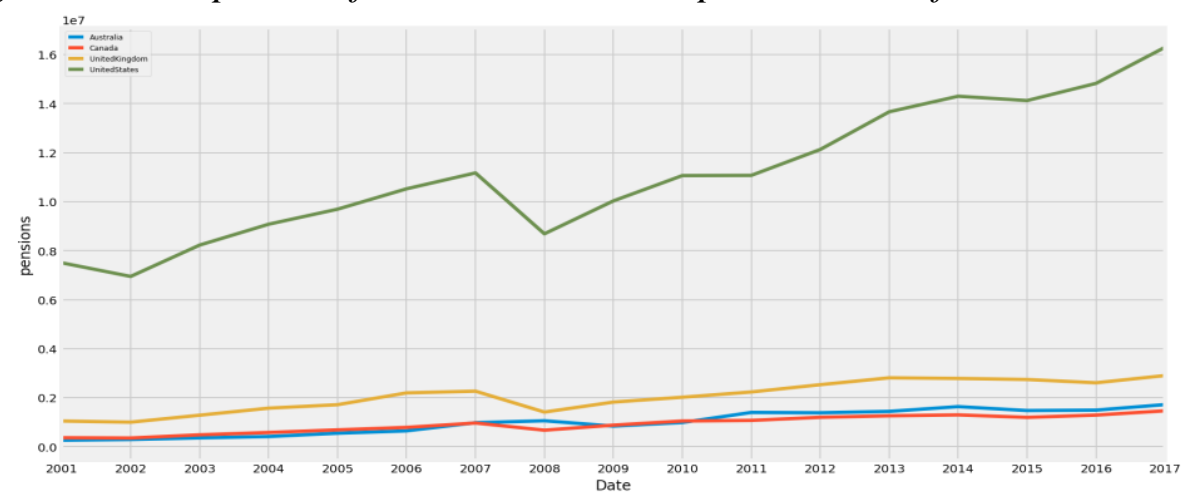

Figure 2. Total pension fund assets in developing countries from 2011 to 2017 In order to make a primary overview of the pension fund assets in countries, we present total pension fund assets. Figure 1 shows the performance in developed countries. One unit of pensions represented by y axis means 10000 billion. We can see that the total value of pension funds in the United States is always larger than other countries, and it experiences a quicker increase from 7504 billion dollars to more than 16000 billion dollars during 2011 and 2017. The United Kingdom also shows an outstanding performance following the United States. The increase from around 1000 billion dollars to nearly 3000 billion dollars for 6 years indicates the strength of a developed capitalist country with a long history. The curves for Australia and Canada get very close and show a similar trend of change.

Figure 2 is for countries in developing countries. One unit of pensions represented by $\mathrm{y}$ axis is 1 million. Among four developing countries, Mexico appears a great growth advantage with high fluctuations. Thailand, Indonesia and Kenya have very close value in 2001, but Thailand grows fastest to more than 25 billion in 2017 among these three countries. Kenya's pension fund assets rise the most slowly, where the change is 


\section{International Academic Conference on Management \& Economics}

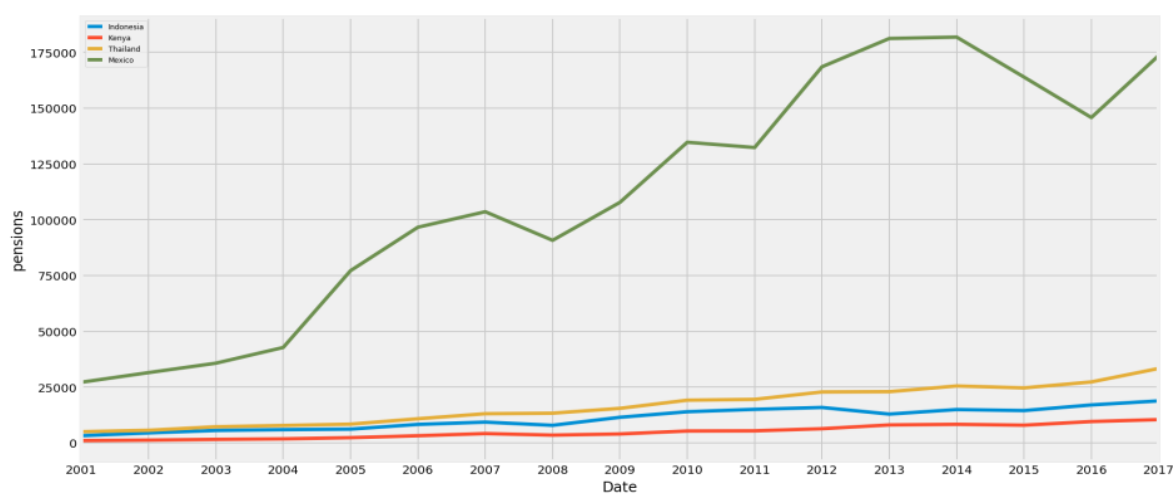

insignificant. It suggests that developing countries still face an unpromising circumstance in pension plans due to the poor economic development.

Overall, each country shows a growing trend, which indicates each has a good development in economy and pension fund service. On the other hand, we also find that most of the countries go through a decrease during 2007 to 2008. The drop might be caused by the financial crisis during 2007 and 2008. According to the U.S. Bureau of Economic Analysis, during the period, the output of goods and services in the United States decreased at an annual rate around 6\%. Tower and Impavido (2009) state that pension fund plans are vulnerable to shocks on both the asset and the liability of balance sheets. During the period of economic regression, pressure on the income statements became a burden for pension plans, which lead to a fall in total pension fund assets.

Figure 3. The rate of return of pension fund investment in developed countries from

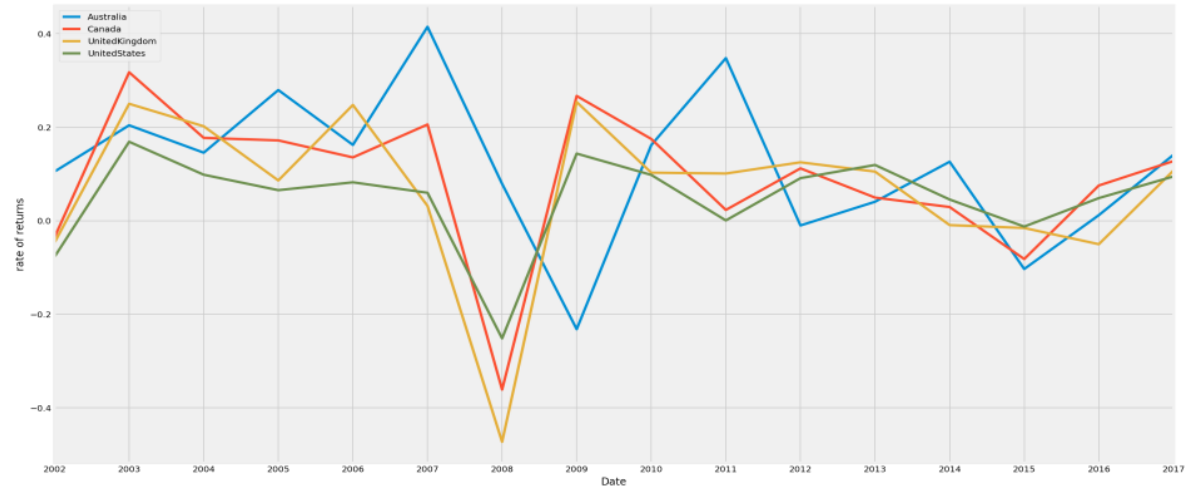




\section{International Academic Conference on Management \& Economics}

2011 to 2017

Figure 4. The rate of return of pension fund investment in developing countries from

2011 to 2017

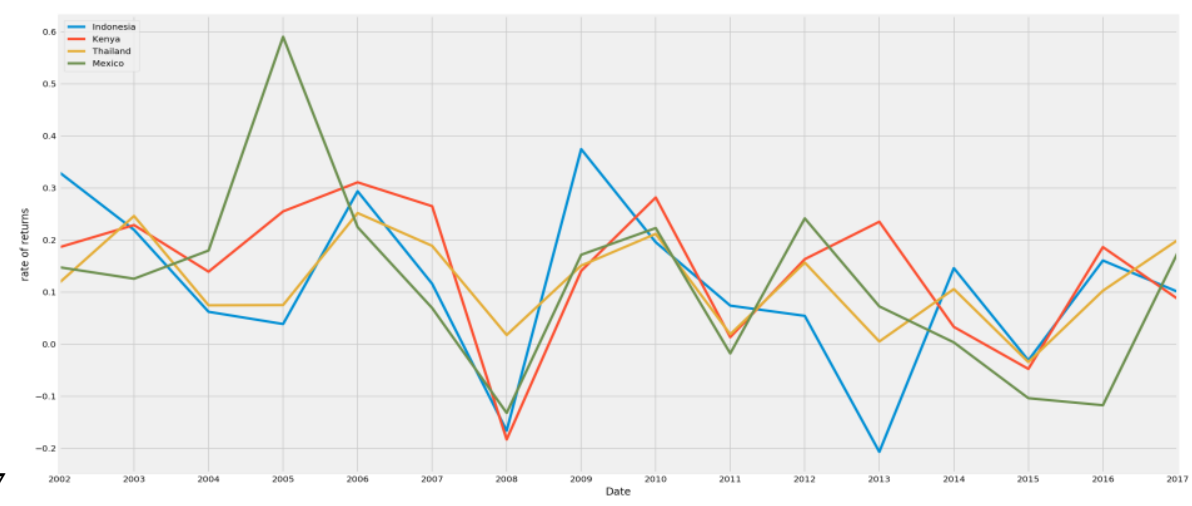

Pension fund plan is substantially an investment technique, so it is essential to analyze the rate of return of pension fund assets for different countries (Figure 3 and Figure 4). In general, positive rate of return indicates that the countries experience a growth of pension fund investment. For developing countries, the rate of return distributes around $10 \%$. Additionally, it should be point out that the rate of return becomes more fluctuated after 2008. Take Mexico as an example, the rate of return becomes negative for three times. It is possible that financial crisis has a continuous influence.

Figure 5. Average annual rate of return and standard deviation of pension fund

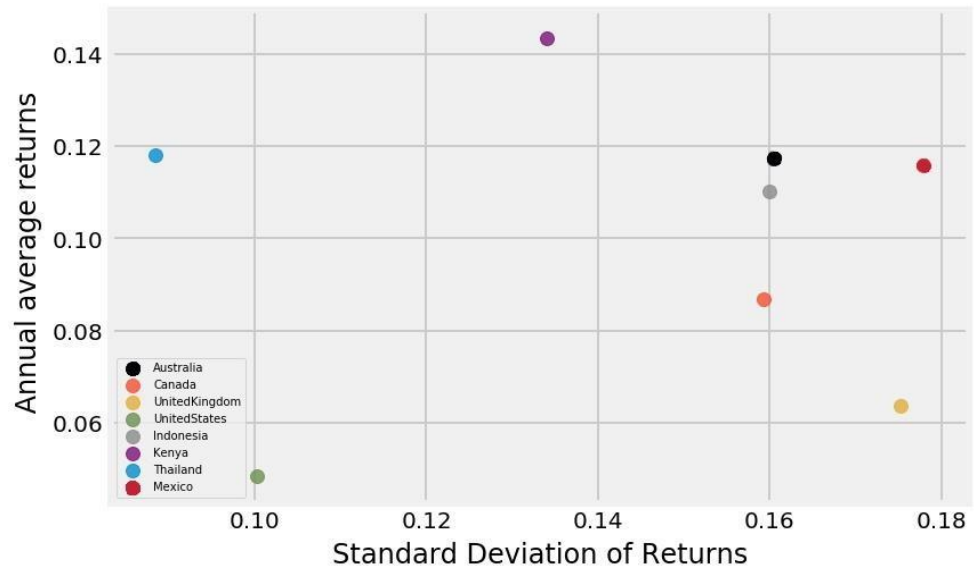




\section{International Academic Conference on Management \& Economics}

To apply mean-variance model in pension plans, we investigate the average rate of return and standard deviation of pension assets in different countries. Points in Figure 5 stand for the expected rate of return (i.e. annual average rate of return) and risk (i.e. standard deviation) of pension fund investment for each country. Most countries have relatively high average returns with relatively high volatility. However, Thailand has achieved a high average return with relatively low risk and the United Kingdom has a high volatility with relatively low average return. Some developed countries such as the United States, the United Kingdom and Canada have a low average return in the period from 2001 to 2017, especially the United States, whose average return and standard deviation is the lowest among the eight countries. In general, average rate of return of pension investment in developing countries is higher than that of developed countries.

\section{Figure. 6 Efficient frontier for portfolio}

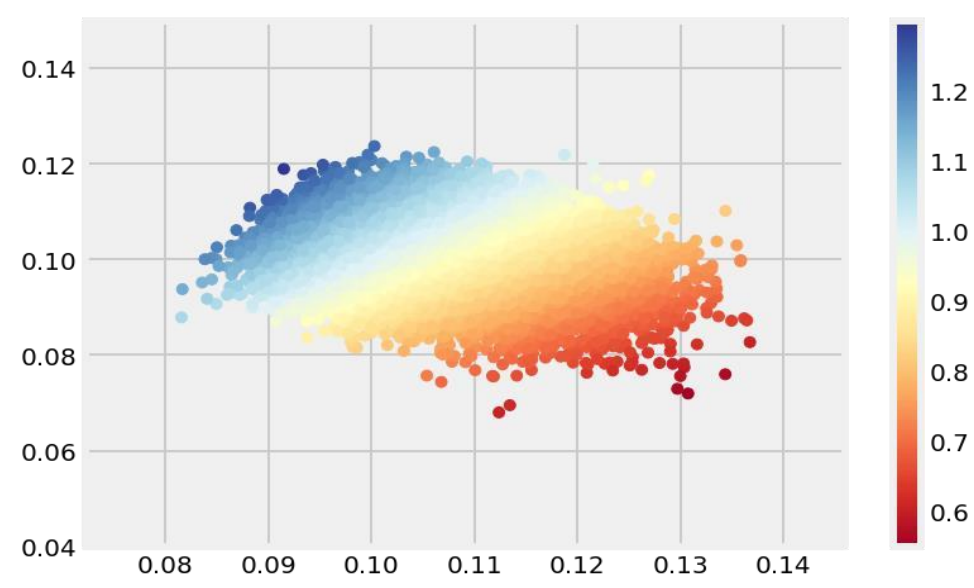

Each pension fund plan can be regarded as an investment conducted by the national government. We assume constructing a pension fund system among these countries to obtain an optimal portfolio and furtherly to maximize the benefit of pension investment plans. As shown in the Figure 6, points which represent the different portfolios with different weights on different countries lead the efficient frontier. The area in blue is preferred by rational investors because it stands for a lower risk at a certain level of return.

In practical, it is difficult to construct a pension fund system among countries because it needs governments to overcome conflicts in politics, society, cultures and so on. As 


\section{International Academic Conference on Management \& Economics}

the results show that the gap between developing countries and developed countries is significantly large. Corporations between countries in pension fund plans can help people in developing countries obtain better pension welfare.

\section{Conclusion}

In this paper, we study the Modern Portfolio Theory in pension fund assets analysis. Firstly, we review previous studies of pension funds and Markowitz's Modern Portfolio Theory. Pension funds is regarded as an investment technique, and it plays an important role in the financial market. We use data of pension fund assets from 8 countries and divide them into 2 groups: developed countries and developing countries. Then we apply mean-variance model to analyze for different countries. We calculate the rate of return and risk (represented by standard deviation) of pension asset investment in each country. We find that each country shows an overall growing trend in pension investment except a drop during 2007 to 2008, which is probably caused by the global financial crisis. Additionally, with a comparison between developed countries and developing countries, we find that the gap between two groups is large. Developed countries significantly dominate developing countries in asset value, for example, the United States occupies the most advantageous position. However, developing countries show a higher growing tendency than developed countries by comparing the average rate of return. Finally, based on different average return and risk of each country obtained, we construct portfolios of country's pension assets with randomly generated weights on each country and obtain an efficient frontier. The results indicate that if we could establish an international pension fund system among countries, it is possible to obtain an optimal portfolio where expected return can be maximized at a given level of risk. However, the efficient frontier line we obtained is not as smooth as that in theoretical model. We can see there are some singular points spreading around. It is probably caused by the data selected from particular countries, but we could not figure out the specific reason behind it. Another reason is that our model is based on some idealized assumptions, which is not realistic in real world. 


\section{International Academic Conference on Management \& Economics}

\section{References}

Bodie, Z. (1988) 'Pension Fund Investment Policy', National Bureau of Economic Research Working Paper Series, No. 2752, pp.27-34. doi: 10.3386/w2752.

Clark, G. L. and Monk, A. H. B. (2006) 'The 'crisis' in defined benefit corporate pension liabilities Part I: Scope of the problem', Pensions: An International Journal, 12(1), pp. 43-54. doi: 10.1057/palgrave.pm.5950041.

Dutta, J., Kapur, S. and Orszag, J. M. (2000) 'A portfolio approach to the optimal funding of pensions', Economics Letters, 69(2), pp. 201-206. doi: 10.1016/S01651765(00)00271-8.

Garon, J.-D. (2016) 'The Commitment Value of Funding Pensions', Economics Letters, 145, pp.11-14. doi:10.1016/j.econlet.2016.04.007.

Goetzmann, W. N. and Ukhov, A. D. (2006) 'British investment overseas 1870-1913: A modern portfolio theory approach', Review of Finance, 10(2), pp. 261-300. doi: 10.1007/s10679-006-8278-2.

Green, M. B. and Clark, G. L. (2000) ‘Pension Fund Capitalism’, Economic Geography, 77(3), pp. 307. doi: 10.2307/3594077.

Højgaard, B. and Vigna, E. (2007) 'Mean-variance portfolio selection and efficient frontier for defined contribution pension schemes', Department of Mathematical Science Aalborg University, [Online]. 1(June), pp. 1-

23. Available:

http://scholar.google.com/scholar?hl=en\&btnG=Search\&q=intitle:MeanVariance+portfolio+selection+and+efficient+frontier+for+defined+contribution+pens ion+schemes\#0.

Impavido, G. and Tower, L. (2009) 'How the Financial Crisis Affects Pensions and Insurance and Why the Impacts Matter', IMF Working Papers, 09 (151), pp. 10-11. doi: 10.5089/9781451872989.001. 


\section{International Academic Conference on Management \& Economics}

Josa-Fombellida, R. and Rincón-Zapatero, J. P. (2008) 'Mean-variance portfolio and contribution selection in stochastic pension funding', European Journal of Operational Research, 187(1), pp. 120-137. doi: 10.1016/j.ejor.2007.03.002.

Lubatkin, M. and Chatterjee, S. (1994) 'Extending Modern Portfolio Theory Into the

Domain of Corporate Diversification: Does It Apply?', Academy of Management Proceedings, 1992(1), pp. 22-26. doi: 10.5465/ambpp.1992.4976644.

Marinoni, O., Adkins, P. and Hajkowicz, S. (2011) 'Water planning in a changing climate: Joint application of cost utility analysis and modern portfolio theory', Environmental Modelling and Software, 26(1), pp. 18-29. doi:

10.1016/j.envsoft.2010.03.001.

Markowitz, H. M. (1952) 'Portfolio Selection', The Journal of Finance, 7(1), pp.77-91. doi:10.1111/j.1540-6261.1952.tb01525.x.

Markowitz, H. M. (1989) 'Mean-Variance Analysis in Portfolio Choice and Capital Markets', The Journal of Finance, 44(2), pp. 531. doi: 10.2307/2328607.

OECD (2018) 'Pension Markets In Focus', OECD, (9), pp. 1-28.

Wu, H. and Zeng, Y. (2015) 'Equilibrium investment strategy for defined-contribution pension schemes with generalized mean-variance criterion and mortality risk',

Insurance: Mathematics and Economics, 64, pp. 396-408. doi: 10.1016/j.insmatheco.2015.07.007.

Yao, H. et al. (2014) 'Asset allocation for a DC pension fund with stochastic income and mortality risk: A multi-period mean-variance framework', Insurance: Mathematics and Economics, 54(1), pp. 84-92. doi: 10.1016/j.insmatheco.2013.10.016. 